\title{
Variation of health-related quality of life assessed by caregivers and patients affected by severe childhood infections
}

Wantanee Kulpeng ${ }^{1,2^{*}}$, Vorasith Sornsrivichai ${ }^{2}$, Virasakdi Chongsuvivatwong ${ }^{2}$, Waranya Rattanavipapong ${ }^{1}$ Pattara Leelahavarong ${ }^{1}$, John Cairns $^{3}$, Yoel Lubell ${ }^{4}$ and Yot Teerawattananon ${ }^{1}$

\begin{abstract}
Background: The agreement between self-reported and proxy measures of health status in ill children is not well established. This study aimed to quantify the variation in health-related quality of life (HRQOL) derived from young patients and their carers using different instruments.

Methods: A hospital-based cross-sectional survey was conducted between August 2010 and March 2011. Children with meningitis, bacteremia, pneumonia, acute otitis media, hearing loss, chronic lung disease, epilepsy, mild mental retardation, severe mental retardation, and mental retardation combined with epilepsy, aged between five to 14 years in seven tertiary hospitals were selected for participation in this study. The Health Utilities Index Mark 2 (HUI2), and Mark 3 (HUI3), and the EuroQoL Descriptive System (EQ-5D) and Visual Analogue Scale (EQ-VAS) were applied to both paediatric patients (self-assessment) and caregivers (proxy-assessment).
\end{abstract}

Results: The EQ-5D scores were lowest for acute conditions such as meningitis, bacteremia, and pneumonia, whereas the HUI3 scores were lowest for most chronic conditions such as hearing loss and severe mental retardation. Comparing patient and proxy scores $(n=74)$, the EQ-5D exhibited high correlation $(r=0.77)$ while in the HUI2 and HUI3 patient and caregiver scores were moderately correlated ( $r=0.58$ and 0.67 respectively). The mean difference between self and proxy-assessment using the HUI2, HUI3, EQ-5D and EQ-VAS scores were 0.03, $0.05,-0.03$ and -0.02 , respectively. In hearing-impaired and chronic lung patients the self-rated HRQOL differed significantly from their caregivers.

Conclusions: The use of caregivers as proxies for measuring HRQOL in young patients affected by pneumococcal infection and its sequelae should be employed with caution. Given the high correlation between instruments, each of the HRQOL instruments appears acceptable apart from the EQ-VAS which exhibited low correlation with the others.

Keywords: Infection, Chronic conditions, Child, Health-related quality of life, Utility, Proxy

\section{Background}

Measuring health-related quality of life (HRQOL) is increasingly used to quantify the effect of a health condition on an individual's life, and to assess the impact of health care interventions. Economic evaluations measure HRQOL in terms of utility, which can be subsequently

\footnotetext{
* Correspondence: wantanee.k@hitap.net

${ }^{1}$ Health Intervention and Technology Assessment Program (HITAP), Ministry of Public Health, Nonthaburi, Thailand

${ }^{2}$ Epidemiology Unit, Faculty of Medicine, Prince of Songkla University, Songkla, Thailand

Full list of author information is available at the end of the article
}

incorporated along with changes in life expectancy in the calculation of Quality-Adjusted Life Years (QALYs) to compare health outcomes across health interventions in different diseases and disabilities to inform resource allocation. Utility scales usually range from 0 to 1 , where full health is assumed to have the value 1 and death the value 0 . Some HRQOL measures such as the Health Utilities Index Mark 2 (HUI2), and Mark 3 (HUI3), and EuroQoL Descriptive System (EQ-5D) allow negative scores that express health states considered worse than death.

\section{C) Biomed Central}


There are difficulties and limitations in assessing HRQOL in young children. Firstly, children's growth and development changes rapidly, which may affect the baseline measure of particular health dimensions such as selfcare, usual activity or communication ability [1,2]. At present, there are no standard instruments for measuring health status in this population. While the HUIs and EQ$5 \mathrm{D}$, generic health status instruments are recognised as valid and reliable for eliciting health status in adults and children aged over four years (for the HUIs and through proxy-assessment) or 14 years (for the EQ-5D) [3-7], and are widely used in cost-utility analysis (CUA) [1,8], their application for younger age-groups is still controversial [1]. Furthermore, HRQOL obtained using different instruments can differ substantially even when measured in the same person $[9,10]$ a phenomenon that is particularly evident in young children. While some variation in HRQOL scores obtained from different instruments is inevitable, these can be tested in target populations in order to explore the extent of variation between them. Instruments that provide widely differing outcomes might then be considered less appropriate for use in these populations.

A second challenge to the use of HRQOL instruments with young children, is that these should ideally be completed by the target population, posing substantial challenges in very young responders. A review found that only $2 \%$ of studies where children were the primary beneficiaries of the intervention estimated HRQOL scores directly from this age-group [1]. This is expected given the greater difficulties children might face in accurately describing their health condition during and after illness episodes. In addition, some of the questions might be too complex for young children to answer. As a result, proxy-assessment, where children's health status is obtained through their caregivers, physicians, or adult patients with similar health conditions, is applied [11-14]. However, self- and proxy-assessed HRQOL scores may vary, even when using the same tools $[12,13]$.

Based on this review, two potential sources of variation are present when assessing HRQOL in young children: 1) variation due to the choice of instrument; 2) variation between the measures obtained from patients directly as opposed to their carers. The agreement between self-reported and proxy measures of health status in ill children is not well established and there are no clear guidelines as to whether this is acceptable practice $[12,13,15,16]$. Where the use of a proxy is not appropriate, better guidance is needed on the most appropriate tools for health status measurement in young children.

This study explores the use of instruments for HRQOL measurement in young children affected by infectious diseases in Thailand, and is a part of a CUA of 10 - and 13-valent pneumococcal conjugate vaccines.
Assessment using various HRQOL instruments by the caregivers and affected children (who are able to rate their health status) can provide the necessary data to address the above knowledge-gap.

The specific objectives of this study are to 1) quantify the variation in scores derived from young patients and their carers using different HRQOL instruments in different health conditions; 2) provide recommendations as to whether it is appropriate to measure HRQOL of paediatric patients using their caregivers' assessments; 3) where proxy assessment is not appropriate, identify which instrument is most suitable for use in very young children.

\section{Methods}

\section{Study design and sample}

The health conditions to be assessed in this study were selected by a consortium of experts in paediatric infectious disease, paediatric neurology, epidemiology, vaccinology, and health economics. The list of conditions aimed to include the most common severe pneumococcal infections and their sequelae that are likely to have the highest impact on HRQOL. The final list included: 1) meningitis 2) bacteremia, 3) pneumonia, 4) acute otitis media (AOM), 5) hearing loss, 6) chronic lung disease, 7) epilepsy, 8) mild mental retardation (MMR), 9) severe mental retardation (SMR), and 10) mental retardation combined with epilepsy (MR + epilepsy).

We conducted a hospital-based cross-sectional survey from August 2010 to March 2011 in seven public tertiary hospitals in different parts of Thailand. The hospitals were selected based on having a high number of bacterial meningitis cases which was a relatively rare condition but one with a high burden of disease. This study was approved by the ethics committee of Queen Sirikit National Institute of Child Health, Nopparat Rajathanee Hospital, Maharat Nakhon Ratchasima Hospital, Udonthani Hospital, Chiangrai Regional Hospital, Hatyai Hospital, and Faculty of Medicine, Prince of Songkla University. We calculated the sample size based on a attempt to detect a mean difference of 0.05 of the maximum of various scales for HRQOL for patientcaregiver pairs with and an estimated standard deviation (SD) of paired response difference of 0.03 [17], a power of $80 \%$ with a significance level of 0.05 , at least six pairs were required for each health condition.

Health personnel from the study sites helped in the identification of eligible patients and their caregivers. Pneumococcal bacteremia, pneumococcal pneumonia and bacterial meningitis cases were identified in the paediatric wards. The case definition for these cases conformed with the clinical criteria defined by the Case Definitions for Infectious Conditions in Thailand [18] or the International Classification of Diseases and Related 
Health Problems $\left(10^{\text {th }}\right.$ edition). AOM, hearing loss, chronic lung disease, epilepsy, MMR, SMR and MR + epilepsy cases were identified in the paediatric clinics. Relevant outpatient cases were classified into each health condition according to physicians' diagnosis, regardless of diagnostic method. We selected all cases who met the criteria during the data collection period.

Patients aged between five and 14 years in the selected hospitals who were diagnosed with any single one of the selected health conditions were enrolled. All school age patients aged 7 years and above who were able to communicate were invited along with their caregivers to directly participate in the study. For patients aged under seven years and for patients who refused or were unable to answer a series of questions, such as those with mental retardation (MR), only caregivers were invited to participate. Caregivers were excluded if they were unable to answer the questions or unwilling to participate in the study.

Consent was sought from a parent or guardian of the identified patients prior to interviews and reviews of paediatric medical records. The participants were interviewed by interviewers using the Thai version of HUIs and EQ-5D questionnaires. Although these instruments can routinely be completed independently by patients, in the study both patients and caregivers were interviewed face-to-face by well-trained interviewers reading out the structured questionnaires and themselves completing the forms.

\section{Study instruments}

The HUI2, HUI3 and EQ-5D were selected as they have been widely used in HRQOL measurement in children and Thai versions have already been validated and approved by the Health Utilities Inc and the EuroQol group, respectively. In addition, responses can be converted into utility scores. The EQ-VAS is an integral component of the EQ-5D questionnaire; however, we examine it here independently of the primary descriptive system. From our literature review, all of these scales were reported to have minimal problem of floor and ceiling effects with the exception of an important ceiling effect in the case of EQ-5D [19-23].

The EQ-5D includes five dimensions (mobility, selfcare, usual activities, pain/discomfort, and anxiety/depression) with three ordered levels of severity for each dimension. The self-administered version of EQ-5D is considered suitable for people aged 14 years and above. An EQ-5D youth (EQ-5D-Y) version for children aged between seven to 12 years has been developed but has not been adapted to the Thai context. The EQ-VAS is a standardised extension to the EQ-5D descriptive system. It is a rating scale with a vertical $20 \mathrm{~cm}$ Visual Analogue Scale (VAS) with the end points labelled best imaginable health state at the top and worst imaginable health state at the bottom having numeric values of 100 and 0 , respectively. The standard version was used for all subjects.

The HUI2 comprises seven dimensions (sensation, mobility, emotion, cognition, self-care, and pain and fertility) with four or five ordered levels of severity for each dimension. The HUI3 was developed to address concerns surrounding certain definitions in the HUI2 [24], and is comprised of eight dimensions (vision, hearing, speech, cognition, pain, emotion, ambulation, and dexterity) with five or six ordered levels of severity for each dimension. Of the seven dimensions in HUI2, the fertility dimension was excluded, whereas the sensation dimension was split into vision, hearing and speech. We used the validated Thai version 'HUI23' [25], which includes all 41 questions that comprise HUI2 (37 questions) and HUI3 (33 questions), and from which each instrument can be used by selecting the relevant components. The HUIs have been considered suitable for people aged five years and above through proxyassessment.

\section{Data analysis}

A Thai algorithm was used to calculate the EQ-5D scores [26] but a Canadian scoring function of HUIs was used for HUI23 due to the lack of local data [27]. The correlation between scores from different instruments was calculated for patients and for caregivers, and the correlation between scores from patients and caregivers was calculated for different instruments. To determine whether there were systematic differences in scores between instruments, we calculated for each health condition and overall HRQOL the mean score and its 95\% confidence interval (CI) using each of the HRQOL instruments in both paediatric patients where possible, and in their caregivers. ANOVA was used to analyze the source of variability of the scores. Differences in scores between caregivers and patients were tested using paired t-tests for the 28 condition-instrument combinations. All statistical analyses were carried out in the open source R software package [28].

\section{Results}

In total 173 cases were identified. None of the caregivers refused to participate giving a $100 \%$ response rate. The number of respondents by health conditions is shown in Table 1. A total of 74 paediatric patient-caregiver complete sets participated in this study. Additionally, 99 caregivers participated with a corresponding patient that was either too sick (all cases of MR and the majority of meningitis, pneumonia and AOM, $n=53$ ) or were too young (aged less than 7 years, $n=46$ ) to complete the questionnaire. The overall mean patient age was $10(\mathrm{SD}=3)$. Males accounted for $62 \%$. Among 
Table 1 Number of assessors by health conditions

\begin{tabular}{lcc}
\hline \multirow{2}{*}{$\begin{array}{c}\text { Health } \\
\text { conditions }\end{array}$} & \multicolumn{2}{c}{ Total 173 cases } \\
\cline { 2 - 3 } & $\begin{array}{c}\text { Assessed by caregivers and } \\
\text { paediatric patients }\end{array}$ & $\begin{array}{c}\text { Assessed by } \\
\text { caregivers alone }\end{array}$ \\
\hline Acute & 7 & 12 \\
Meningitis & 9 & 7 \\
Bacteremia & 8 & 16 \\
Pneumonia & 7 & 11 \\
AOM & 15 & 7 \\
Sequalae & 12 & 4 \\
Hearing loss & & 4 \\
Chronic lung & 16 & 8 \\
disease & 0 & 11 \\
Epilepsy & 0 & $\mathbf{9 9}$ \\
MMR & 0 & \\
SMR & & \\
MR + & $\mathbf{7 4}$ & \\
epilepsy & & \\
Total & &
\end{tabular}

173 caregivers, the mean age was 40 years $(S D=11)$ and males accounted for only $13 \%$. The duration for completing the HUI23 was approximately eight minutes in both patients and caregivers, significantly longer than for the EQ-5D + VAS which took approximately three minutes.

Table 2 shows correlation coefficients among different instruments in the same subjects (both the patient and caregiver) and between the same patient-caregiver pair using the same instrument (highlighted in the bold). Most values indicated relatively high or moderate correlation except the correlation coefficients between the EQ-VAS and HUIs, both within the same person and between patient and caregiver in the same pair.
The HRQOL scores obtained from all caregivers are shown in Figure 1. The EQ-5D scores are the lowest for seven of 10 health conditions i.e., meningitis, bacteremia, pneumonia, AOM, chronic lung disease, epilepsy and MMR, whereas the HUI3 gave the lowest scores for three health conditions i.e., hearing loss, SMR and MR + epilepsy. The HRQOL scored by paediatric patients themselves are shown in Figure 2. Similarly, the EQ-5D scores were lowest among four of the seven health conditions in which patients could respond i.e., meningitis, bacteremia, pneumonia and epilepsy. Likewise, the HUI3 scores were lowest in the remaining three conditions. We ran a factor analysis for the mean of each measure on each health condition. Two factors were identified in both caregiver and patient data sets. In both groups, the first factor included meningitis, bacteremia, pneumonia, chronic lung disease and epilepsy. The second factor had less consistent components. The total variances of these means explained by the two factors were $94 \%$ in caregivers and $98 \%$ in patients.

Table 3 illustrates the source of variation in HRQOL scores in the two data sets. Using data from the complete sets, variation within the same patientcaregiver pair was small and not significant $(P=0.59)$. Variation contributed by difference in the health conditions and instruments were highly significant in both data sets. When accounting for interaction between the health conditions and instruments, the $P$ was small indicating that both health conditions and instruments were not acting independently from each other.

Table 4 shows the breakdown of differences within caregiver-patient sets by health condition and instruments. HRQOL reported by paediatric patients were slightly and non-significantly higher than those

Table 2 Matrix of scores obtained in paediatric patients and caregivers using 4 HRQOL instruments $(N=74)$

\begin{tabular}{|c|c|c|c|c|c|c|c|}
\hline & \multicolumn{3}{|c|}{ Scores from caregiver } & \multicolumn{4}{|c|}{ Scores from patient } \\
\hline & HUI3 & EQ-5D & $\overline{\text { EQ-VAS }}$ & HUI2 & HUI3 & EQ-5D & $\overline{\text { EQ-VAS }}$ \\
\hline \multicolumn{8}{|c|}{ Scores from caregiver } \\
\hline HUI2 & 0.84 & 0.63 & 0.43 & 0.58 & 0.57 & 0.56 & $0.20^{\mathrm{a}}$ \\
\hline HUI3 & & 0.69 & 0.50 & 0.58 & 0.67 & 0.59 & 0.24 \\
\hline EQ-5D & & & 0.55 & 0.40 & 0.44 & 0.77 & 0.49 \\
\hline EQ-VAS & & & & $0.11^{\mathrm{a}}$ & $0.20^{\mathrm{a}}$ & 0.40 & 0.50 \\
\hline \multicolumn{8}{|c|}{ Scores from patient } \\
\hline HUI3 & & & & 0.89 & & & \\
\hline EQ-5D & & & & 0.59 & 0.58 & & \\
\hline EQ-VAS & & & & $0.11^{\mathrm{a}}$ & $0.16^{\mathrm{a}}$ & 0.37 & \\
\hline
\end{tabular}

Values in bold correspond to the correlation coefficients of the scores between the patients and the caregivers using the same instruments. ${ }^{a}$ The correlation is found to be non-significant $(P>0.05)$. 


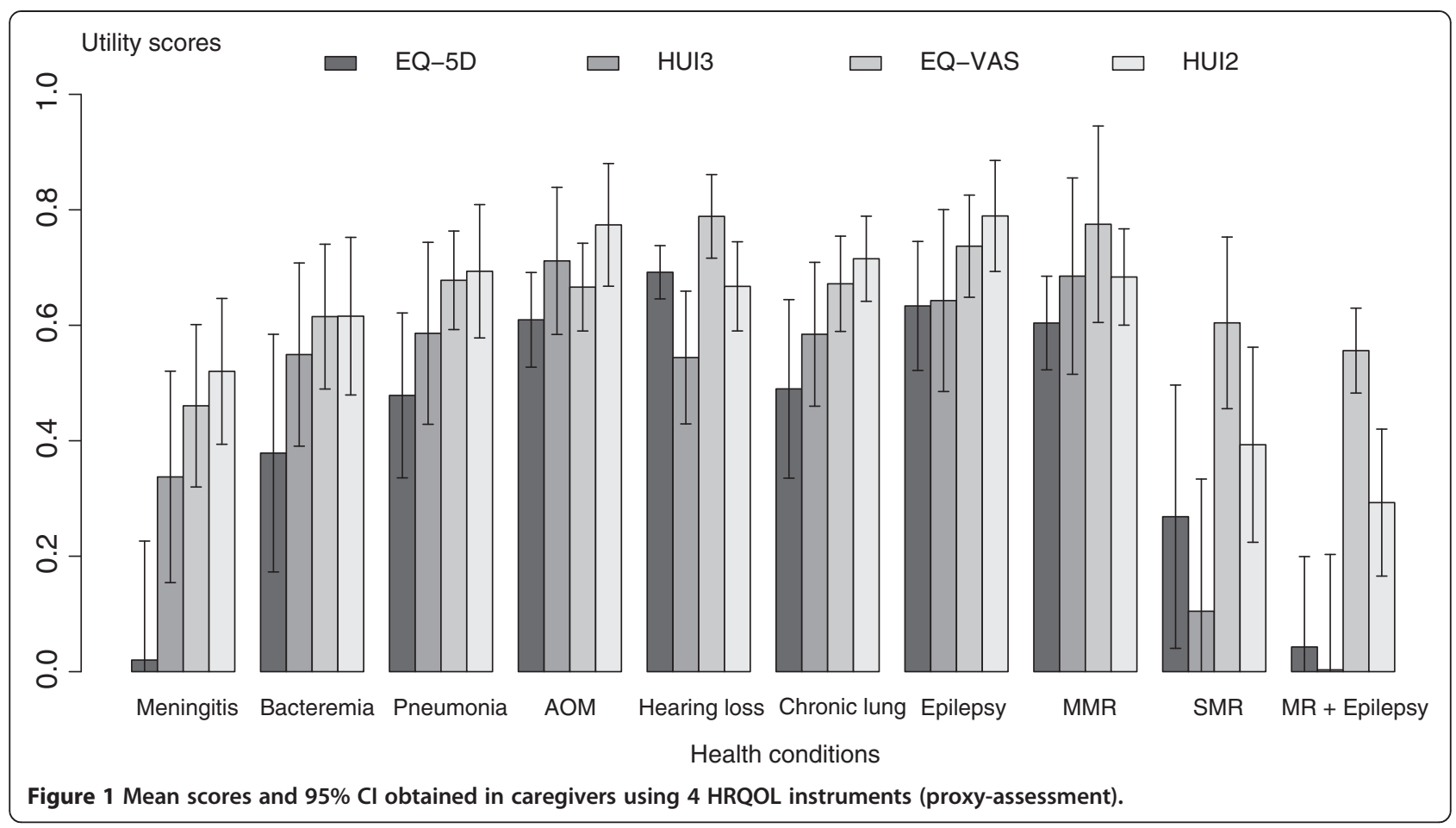

reported by caregivers. The only significant difference detected within the pairs was for hearing loss using HUI3 and chronic lung disease using EQ-5D.

\section{Discussion}

This is the first study considering methodological aspects of children's HRQOL instruments in the Thai context and results of this study can be useful for guiding future economic evaluations or outcome studies in this and other settings. In this analysis, we address two major methodological issues concerning the use of caregivers as proxies for children's HRQOL measures, and the use of different HRQOL instruments across health conditions in young patients.

The variation in HRQOL derived from patients compared to their caregivers

We observed disparity in HRQOL derived from young patients and caregivers using all instruments, and the mean of differences exceeded 0.03 , a difference that has been considered to be clinically significant by previous investigators $[7,9,29]$. Likewise, the data in Table 4

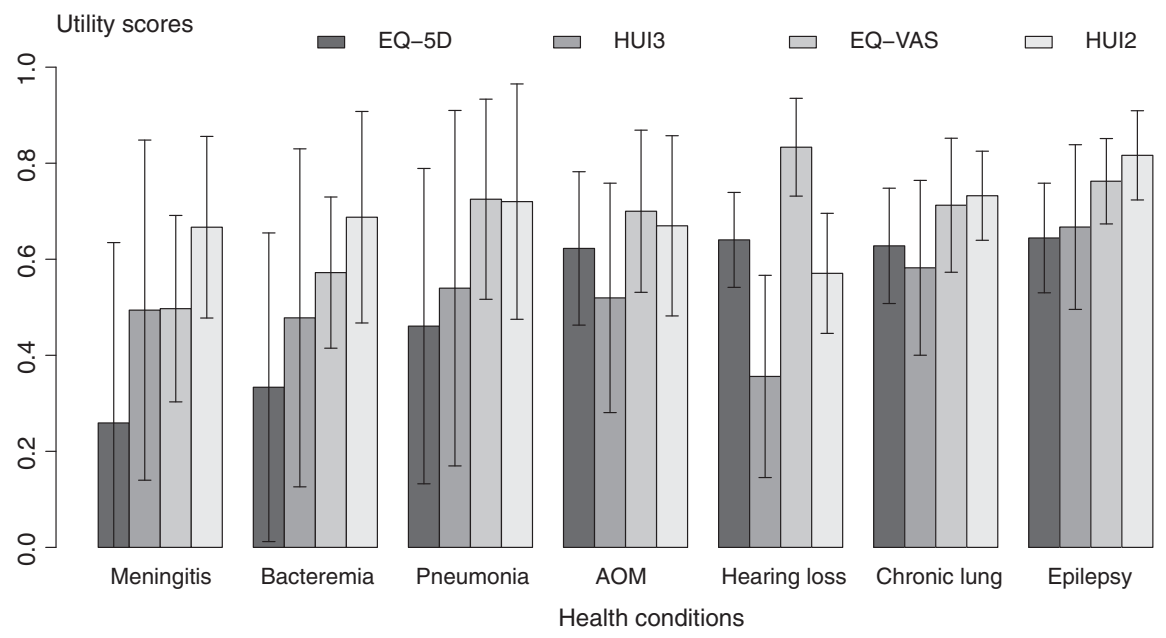

Figure 2 Mean scores and $95 \% \mathrm{Cl}$ obtained in paediatric patients using $4 \mathrm{HRQOL}$ instruments (self-assessment). 
Table 3 Comparison of mean scores by sources

\begin{tabular}{|c|c|c|c|c|c|}
\hline & Df & SS & MS & $\mathbf{F}$ & P-value \\
\hline \multicolumn{6}{|c|}{ From caregivers and patients complete sets } \\
\hline Assessor & 1 & 0.02 & 0.02 & 0.28 & 0.59 \\
\hline Health condition & 6 & 4.02 & 0.67 & 9.57 & $<0.001$ \\
\hline Instrument & 3 & 3.85 & 1.28 & 18.31 & $<0.001$ \\
\hline Health condition : instrument & 18 & 2.99 & 0.17 & 2.49 & $<0.001$ \\
\hline Residuals & 581 & 40.66 & 0.07 & & \\
\hline \multicolumn{6}{|l|}{ From sets with caregivers only } \\
\hline Health condition & 9 & 15.29 & 1.70 & 27.38 & $<0.001$ \\
\hline Instrument & 3 & 3.51 & 1.05 & 16.92 & $<0.001$ \\
\hline Health condition : instrument & 27 & 3.12 & 0.12 & 1.86 & $<0.01$ \\
\hline Residuals & 652 & 40.47 & 0.06 & & \\
\hline
\end{tabular}

suggest that the difference between patients and caregivers was in the majority of health conditions of a magnitude which would be regarded as clinically meaningful though not statistically significant (except for hearing loss and chronic lung disease using particular instruments). The largest gap was found in hearing loss. Health conditions relating to sensory impairment such as hearing loss might be more challenging in proxyassessment than objective measures such as mobility.

The variation in HRQOL scores derived from patients compared to their caregivers was also associated with HRQOL instruments. The HUIs and EQ-5D scores had good correlation within patient-caregiver pairs, a finding that is also compatible with other studies $[14,30,31]$. The degree of caregiver-patient correlation in the HUI3 was higher than in the HUI2 in our study. The EQ-VAS in both patients and caregivers had the lowest correlation with other measures. This may be because the EQ-VAS involves a different task (valuation of health state) whereas for the other three measures the respondents were asked to describe their own or the child's health state.

The use of different HRQOL instruments across health conditions in young patients

As would be expected, all instruments offered different HRQOL scores for the same health condition. For both self- and proxy-assessment, the EQ-VAS and HUI2 gave

Table 4 Mean of difference of scores between caregivers and paediatric patients

\begin{tabular}{|c|c|c|c|c|c|c|}
\hline \multirow[b]{2}{*}{ Health conditions } & & \multirow[b]{2}{*}{$N$} & \multicolumn{4}{|c|}{ Mean of difference } \\
\hline & & & HUI2 & HUI3 & EQ-5D & EQ-VAS \\
\hline \multirow[t]{2}{*}{ Meningitis } & & 7 & -0.07 & -0.07 & -0.27 & 0.05 \\
\hline & $(95 \% \mathrm{Cl})$ & & $(-0.17$ to 0.03$)$ & $(-0.21$ to 0.07$)$ & $(-0.58$ to 0.05$)$ & (-0.09 to 0.20$)$ \\
\hline \multirow[t]{2}{*}{ Bacteremia } & & 9 & 0.05 & 0.13 & 0.08 & 0.01 \\
\hline & $(95 \% \mathrm{Cl})$ & & $(-0.15$ to 0.24$)$ & $(-0.18$ to 0.44$)$ & $(-0.13$ to 0.29$)$ & $(-0.19$ to 0.21$)$ \\
\hline \multirow[t]{2}{*}{ Pneumonia } & & 8 & -0.08 & -0.02 & -0.05 & -0.05 \\
\hline & $(95 \% \mathrm{Cl})$ & & $(-0.22$ to 0.07$)$ & $(-0.13$ to 0.10$)$ & $(-0.15$ to 0.05$)$ & $(-0.28$ to 0.17$)$ \\
\hline \multirow[t]{2}{*}{$\mathrm{AOM}$} & & 7 & 0.05 & 0.07 & -0.08 & -0.06 \\
\hline & $(95 \% \mathrm{Cl})$ & & $(-0.09$ to 0.19$)$ & $(-0.09$ to 0.24$)$ & $(-0.20$ to 0.04$)$ & $(-0.23$ to 0.11$)$ \\
\hline \multirow[t]{2}{*}{ Hearing loss } & & 15 & 0.14 & 0.24 & 0.08 & 0.01 \\
\hline & $(95 \% \mathrm{Cl})$ & & $(-0.01$ to 0.28$)$ & $(0.03 \text { to } 0.46)^{a}$ & $(-0.03$ to 0.19$)$ & $(-0.12$ to 0.14$)$ \\
\hline \multirow[t]{2}{*}{ Chronic lung } & & 12 & 0.00 & 0.03 & -0.11 & -0.03 \\
\hline & $(95 \% \mathrm{Cl})$ & & $(-0.11$ to 0.12$)$ & ( -0.09 to 0.14$)$ & $(-0.22 \text { to }-0.00)^{a}$ & ( -0.16 to 0.09$)$ \\
\hline \multirow[t]{2}{*}{ Epilepsy } & & 16 & -0.01 & 0.00 & -0.00 & -0.02 \\
\hline & $(95 \% \mathrm{Cl})$ & & $(-0.08$ to 0.07$)$ & (-0.11 to 0.12$)$ & $(-0.06$ to 0.06$)$ & ( -0.10 to 0.06$)$ \\
\hline \multirow[t]{2}{*}{ Overall } & & 74 & 0.03 & 0.05 & -0.03 & -0.02 \\
\hline & $(95 \% \mathrm{Cl})$ & & $(-0.02$ to 0.07$)$ & $(-0.00$ to 0.11$)$ & $(-0.07$ to 0.02$)$ & $(-0.06$ to 0.02$)$ \\
\hline
\end{tabular}

${ }^{a}$ Statistically significant $(P<0.05)$ different utility score for caregivers compared with patients. 
the highest scores whereas the EQ-5D and HUI3 tended to provide the lowest. The EQ-5D yielded the lowest HRQOL scores compared to other instruments in acute diseases, whereas the HUI3 provided the lowest score in most of chronic conditions. These findings are consistent with two other studies $[10,32]$. Our study, however, found that for epilepsy the HRQOL score was the lowest using the EQ-5D, as opposed to HUI3 in another study [10]. It is noteworthy that the Thai algorithm used for EQ-5D was derived from the Time Trade-Off (TTO) technique, whereas HUI scoring function was obtained from the Standard Gamble (SG) technique and VAS. This difference might influence the results because previous studies indicated that TTO produced lower utility scores than SG in Asian and other population groups [33-36]. Moreover, the absence of a Thai specific scoring function for HUIs could have affected the results as people in different countries are likely to have different health state preferences [32].

The EQ-5D in particular may not be sufficiently sensitive for measuring HRQOL in patients with sensory impairment as it does not include a sensory dimension [32,37-39]. SG and TTO have been used to measure utility directly in hearing impaired persons [40]. The SG and TTO, however, are time-consuming and conceptually challenging. Furthermore, the HUI3 has proven to be valid and acceptable for measuring HRQOL in hearing impaired populations [10,32,37-39,41]. For health conditions associated with sensory impairment, therefore, self-reported assessment of health status using the HUI3 is the optimal choice. The EQ-VAS score obtained from patients and caregivers is similar, yet correlation between scores rated by this and other instruments was low. Furthermore, given the general difficulties in using the EQ-VAS in people who may not understand its quantitative properties $[33,42,43]$, it may not be appropriate for very young patients. This was supported by a prior study showing that $13 \%$ of adult patients found it difficult to use [43].

In addition, the degree of correlation between instruments is used to examine their agreement (convergent validity). The HUIs and EQ-5D scores had a moderate to high correlation within the same subject, confirming findings from previous studies [44-46]. The HUI2 and HUI3 had very high correlation; this is mainly because there is much duplication in these tools (30 of 40 questions in HUI23 are identical). The HUI3 is claimed to be superior to the HUI2 as it was developed to improve structural independence so that each domain would yield specific information [24,47].

\section{Study limitations}

In addition to the limitation of incomplete pairs of patient-caregiver sets, another methodological concern is the fact that subjects were recruited at tertiary hospitals where patients are likely to be in an acute phase of their illness and the impact on certain HRQOL dimensions such as mobility may not be readily apparent. We argue that this did not introduce a substantial bias since patients in most of our pre-specified conditions are usually hospitalized. The shortcoming may be more serious in health states associated with chronic disability as patient and proxy assessment of their HRQOL once back home may be different from when they are hospitalized [48]. Lastly, although this study selected patients with a single condition, there may have been co-morbidities that were undiagnosed during data collection that may have influenced HRQOL scores.

\section{Conclusions}

Our data imply that use of caregivers as proxies for measuring HRQOL in young patients affected by pneumococcal infection and its sequelae should be employed with caution. Given the high correlation between instruments, each of the HRQOL instruments appears acceptable apart from the EQ-VAS which exhibited low correlation with the others. For conditions associated with sensory impairment we would recommend the use of HUI3 due to its explicit inclusion of this dimension.

\section{Abbreviations \\ HRQOL: Health-related quality of life; QALYs: Quality-adjusted life years; HUI2: Health Utilities Index Mark 2; HUI3: Health Utilities Index Mark 3; EQ- 5D: EuroQoL Descriptive System; VAS: Visual Analogue Scale; TTO: Time Trade-Off; SG: Standard Gamble; CUA: Cost-utility analysis; AOM: Acute otitis media; MR: Mental retardation; MMR: Mild mental retardation; SMR: Severe mental retardation; MR + epilepsy: Mental retardation combined with epilepsy; Cl: Confidence interval; SD: Standard deviation; $r$ : Correlation coefficient.}

\section{Competing interests}

The authors declare that they have no completing interests.

\section{Authors' contributions}

WK, VS, VC, JC and YT contributed to conception and study design. WK and VC analyzed and interpreted data. WK drafted the manuscript. All authors contributed to the analysis and revised the manuscript. All authors read and approved the final manuscript.

\section{Acknowledgements}

We would like to thank the Thailand Research Fund under the Senior Research Scholar on Health Technology Assessment (RTA5580010), the National Health Security Office, the Thai Health Promotion Foundation, the Health System Research Institute and the Bureau of Health Policy and Strategy, Ministry of Public Health for funding support through the Health Intervention and Technology Assessment Program (HITAP). We are grateful for the support from Health Utilities Inc. and the EuroQoL group. We wish to acknowledge the valuable information provided by the Bureau of Epidemiology, Department of Disease Control, and the Department of Medical Sciences. We are also thankful for all respondents and hospitals officers for their participation to the study. Finally, we would like to thank Wit Wichaidit and Walailuk Jitpiboon for their contribution to data management. 


\section{Author details}

'Health Intervention and Technology Assessment Program (HITAP), Ministry of Public Health, Nonthaburi, Thailand. 'Epidemiology Unit, Faculty of Medicine, Prince of Songkla University, Songkla, Thailand. ${ }^{3}$ London School of Hygiene and Tropical Medicine, London, United Kingdom. ${ }^{4}$ Mahidol Oxford Tropical Medicine Research Unit, Faculty of Tropical Medicine, Mahidol University, Bangkok, Thailand.

Received: 18 April 2013 Accepted: 7 August 2013

Published: 13 August 2013

\section{References}

1. Griebsch I, Coast J, Brown J: Quality-adjusted life-years lack quality in pediatric care: a critical review of published cost-utility studies in child health. Pediatrics 2005, 115:e600-e614.

2. Klassen AF, Landgraf JM, Lee SK, Barer M, Raina P, Chan HW, Matthew D, Brabyn D: Health related quality of life in 3 and 4 year old children and their parents: preliminary findings about a new questionnaire. Health Qual Life Outcomes 2003, 1:81.

3. Bushnell DM, Martin ML, Ricci JF, Bracco A: Performance of the EQ-5D in patients with irritable bowel syndrome. Value Health 2006, 9:90-97.

4. Schweikert B, Hahmann H, Leidl R: Validation of the EuroQol questionnaire in cardiac rehabilitation. Heart 2006, 92:62-67.

5. Szecket N, Medin G, Furlong WJ, Feeny DH, Barr RD, Depauw S: Preliminary translation and cultural adaptation of Health Utilities Index questionnaires for application in Argentina. Int J Cancer Suppl 1999, 12:119-124.

6. Glaser AW, Furlong W, Walker DA, Fielding K, Davies K, Feeny DH, Barr RD: Applicability of the Health Utilities Index to a population of childhood survivors of central nervous system tumours in the U.K. Eur J Cancer 1999, 35:256-261.

7. Drummond $\mathrm{M}$ : Introducing economic and quality of life measurements into clinical studies. Ann Med 2001, 33:344-349.

8. David A, Alan G, Andrew S, Richard L: Comparison of direct and indirect methods of estimating health state utilities for resource allocation: review and empirical analysis. BMJ 2009, 339:b2688.

9. Wee HL, Machin D, Loke WC, Li SC, Cheung YB, Luo N, Feeny D, Fong KY, Thumboo J: Assessing differences in utility scores: a comparison of four widely used preference-based instruments. Value Health 2007, 10:256-265

10. Oostenbrink R, HA AM, Essink-Bot ML: The EQ-5D and the health utilities index for permanent sequelae after meningitis: a head-to-head comparison. J Clin Epidemiol 2002, 55:791-799.

11. Bennett JE, Summer W II, Downs SM, Jaffe DM: Parents' Utilities for outcomes of occult bacteremia. Arch Pediatr Adolesc Med 2000, 154:43-48.

12. Baca CB, Vickrey BG, Hays RD, Vassar SD, Berg AT: Differences in child versus parent reports of the child's health-related quality of life in children with epilepsy and healthy siblings. Value Health 2010, 13:778-786.

13. Eiser C, Morse R: Can parents rate their child's health-related quality of life? results of a systematic review. Qual Life Res 2001, 10:347-357.

14. Klaassen RJ, Barr RD, Hughes J, Rogers P, Anderson R, Grundy P, Ali SK, Yanofsky R, Abla O, Silva M, et al: Nurses provide valuable proxy assessment of the health-related quality of life of children with Hodgkin disease. Cancer 2010, 116:1602-1607.

15. Loonen HJ, Derkx BH, Koopman HM, Heymans HS: Are parents able to rate the symptoms and quality of life of their offspring with IBD? Inflamm Bowel Dis 2002, 8:270-276.

16. Sung L, Young NL, Greenberg ML, McLimont M, Samanta T, Wong J, Rubenstein J, Ingber S, Doyle JJ, Feldman BM: Health-related quality of life (HRQL) scores reported from parents and their children with chronic illness differed depending on utility elicitation method. J Clin Epidemiol 2004, 57:1161-1166.

17. Stade BC, Stevens B, Ungar WJ, Beyene J, Koren G: Health-related quality of life of Canadian children and youth prenatally exposed to alcohol. Health Qual Life Outcomes 2006, 4:81.

18. Bureau of Epidemiology: Case definitions for infectious conditions in Thailand, 2001. 1st edition. Bangkok: The Express Transportation Organization of Thailand (ETO); 2001.

19. Davison SN, Jhangri GS, Feeny DH: Comparing the health utilities index mark 3 (HUI3) with the short form-36 preference-based SF-6D in chronic kidney disease. Value Health 2009, 12:340-345.
20. Guo N, Marra CA, Marra F, Moadebi S, Elwood RK, Fitzgerald JM: Health state utilities in latent and active tuberculosis. Value Health 2008 , 11:1154-1161

21. Harrison MJ, Davies LM, Bansback NJ, McCoy MJ, Verstappen SM, Watson K, Symmons DP: The comparative responsiveness of the EQ5D and SF-6D to change in patients with inflammatory arthritis. Qual Life Res 2009, 18:1 195-1205.

22. Zhou HJ, So JB, Yong WP, Luo N, Zhu F, Naidoo N, Li SC, Yeoh KG: Validation of the functional assessment of cancer therapy-gastric module for the Chinese population. Health Qual Life Outcomes 2012, 10:145.

23. Dyer MT, Goldsmith KA, Sharples LS, Buxton MJ: A review of health utilities using the EQ-5D in studies of cardiovascular disease. Health Qual Life Outcomes 2010, 8:13.

24. Horsman J, Furlong W, Feeny D, Torrance G: The health utilities index (HUI): concepts, measurement properties and applications. Health Qual Life Outcomes 2003, 1:54

25. Questionnaire development, translations and support. http://www. healthutilities.com/

26. Tongsiri S, Cairns J: Estimating population-based values for EQ-5D health states in Thailand. Value Health 2011, 14:1142-1145.

27. Health Utilities Inc: Procedures manual. Ontario; 2002.

28. R Development Core Team: R: A language and environment for statistical computing. In Book $R$ : A language and environment for statistical computing; 2011.

29. Samsa G, Edelman D, Rothman ML, Williams GR, Lipscomb J, Matchar D: Determining clinically important differences in health status measures: a general approach with illustration to the health utilities index mark II. Pharmacoeconomics 1999, 15:141-155.

30. Naglie G, Tomlinson G, Tansey C, Irvine J, Ritvo P, Black SE, Freedman M, Silberfeld M, Krahn M: Utility-based quality of life measures in Alzheimer's disease. Qual Life Res 2006, 15:631-643.

31. Pickard AS, Johnson JA, Feeny DH, Shuaib A, Carriere KC, Nasser AM: Agreement between patient and proxy assessments of health-related quality of life after stroke using the EQ-5D and health utilities index. Stroke 2004, 35:607-612.

32. Grutters JP, Joore MA, van der Horst $F$, Verschuure $H$, Dreschler WA Anteunis LJ: Choosing between measures: comparison of EQ-5D, HUI2 and $\mathrm{HUI} 3$ in persons with hearing complaints. Qual Life Res 2007, 16:1439-1449

33. Wee HL, Li SC, Xie F, Zhang XH, Luo N, Feeny D, Cheung YB, Machin D, Fong KY, Thumboo J: Validity, feasibility and acceptability of time tradeoff and standard gamble assessments in health valuation studies: a study in a multiethnic Asian population in Singapore. Value Health 2008, 11(Suppl 1):S3-S10.

34. Doctor JN, Zoellner LA, Feeny NC: Predictors of health-related quality-of -life utilities among persons with posttraumatic stress disorder. Psychiatr Serv 2011, 62:272-277.

35. Sinno H, Thibaudeau S, Tahiri Y, Mok E, Christodoulou G, Lessard L, Williams B, Lin SJ: Utility assessment of body contouring after massive weight loss. Aesthetic Plast Surg 2011, 35:724-730.

36. Sun X, Zhang S, Wang N, Liang Y, Wang L, Fan S, Sun L: Utility assessment among patients of primary angle closure/glaucoma in China: a preliminary study. Br J Ophthalmol 2009, 93:871-874.

37. Bess $\mathrm{FH}$ : The role of generic health-related quality of life measures in establishing audiological rehabilitation outcomes. Ear Hear 2000, 21:745-795.

38. Joore MA, Brunenberg DE, Chenault MN, Anteunis LJ: Societal effects of hearing aid fitting among the moderately hearing impaired. Int I Audiol 2003, 42:152-160.

39. Vuorialho A, Karinen P, Sorri M: Effect of hearing aids on hearing disability and quality of life in the elderly. Int J Audiol 2006, 45:400-405.

40. Carroll AE, Downs SM: Improving decision analyses: parent preferences (utility values) for pediatric health outcomes. J Pediatr 2009, 155:21-25. 25 e21-25.

41. Petrou S, McCann D, Law CM, Watkin PM, Worsfold S, Kennedy CR: Health status and health-related quality of life preference-based outcomes of children who are aged 7 to 9 years and have bilateral permanent childhood hearing impairment. Pediatrics 2007, 120:1044-1052.

42. Sakthong P: Measurement of clinical-effect: utility. J Med Assoc Thai 2008 , 91(2):S43-S52 
43. Mohan H, Ryan J, Whelan B, Wakai A: The end of the line? the visual analogue scale and verbal numerical rating scale as pain assessment tools in the emergency department. Emerg Med J 2010, 27:372-375.

44. BioPsychoSocial assessment tools for the elderly - assessment summary sheet. http://instruct.uwo.ca/kinesiology/9641/Assessments/Biological/EQ-5D.html

45. McDonough CM, Grove MR, Tosteson TD, Lurie JD, Hilibrand AS, Tosteson AN: Comparison of EQ-5D, HUI, and SF-36-derived societal health state values among spine patient outcomes research trial (SPORT) participants. Qual Life Res 2005, 14:1321-1332.

46. Gibbons E, Fitzpatrick R: A stuctured review of patient-reported outcome measures for people with asthma:an update 2009. In Book A stuctured review of patient-reported outcome measures for people with asthma:an update 2009. Patient-reported Outcome Measurement Group, Department of Public Health, University of Oxford; 2009.

47. Legood R, Coen PG, Knox K, Viner RM, El Bashir H, Christie D, Patel BC, Booy $R$ : Health related quality of life in survivors of pneumococcal meningitis. Acta Paediatr 2009, 98:543-547.

48. Speyer E, Herbinet A, Vuillemin A, Chastagner P, Briancon S: Agreement between children with cancer and their parents in reporting the child's health-related quality of life during a stay at the hospital and at home. Child Care Health Dev 2009, 35:489-495.

doi:10.1186/1471-2431-13-122

Cite this article as: Kulpeng et al:: Variation of health-related quality of life assessed by caregivers and patients affected by severe childhood infections. BMC Pediatrics 2013 13:122.

\section{Submit your next manuscript to BioMed Central} and take full advantage of:

- Convenient online submission

- Thorough peer review

- No space constraints or color figure charges

- Immediate publication on acceptance

- Inclusion in PubMed, CAS, Scopus and Google Scholar

- Research which is freely available for redistribution 